\title{
Erratum: Spontaneous Mediastinal Emphysema
}

Devina Singh ${ }^{1}$, Sanjana Kumar ${ }^{2}$, Thor S. Stead ${ }^{3}$, Latha Ganti ${ }^{4}$

1. Medicine, University of Louisville 2. Molecular and Cell Biology, University of California, Berkeley 3. Student, Alpert Medical School of Brown University 4. Clinical Sciences, University of Central Florida College of Medicine, Orlando, USA

$\square$ Corresponding author: Thor S. Stead, stead4@gmail.com

Disclosures can be found in Additional Information at the end of the article

Corresponding author: Thor S. Stead

1. Medicine, University of Louisville 2. Molecular and Cell Biology, University of California, Berkeley 3. Student, Alpert Medical School of Brown University 4. Clinical Sciences, University of Central Florida College of Medicine, Orlando, USA

How to cite this erratum

Singh D, Kumar S, Stead T S, et al. (August 10, 2018) Correction: Spontaneous Mediastinal Emphysema. Cureus $10(8)$ : c15. doi:10.7759/cureus.c15

\section{Correction Notice}

The first paragraph of the Discussion section erroneously referred to forceful vomiting as "Boerhaave's syndrome." While forceful vomiting is a feature of Boerhaaves syndrome, there is more to the syndrome than just this, and Boerhaave's is not a benign disease, while spontaneous mediastinal emphysema often is.

As such, the reference to Boerhaave's syndrome has been removed from the article. 